pipping and hatching, and that this shortening of the ineubation period is due to the proximity of the more advanced eggs in each clutch.

These results are consistent with the viow that there is, in this species, a mechanism acting between eggs which tends to synchronize the embryos' development towards the time of hatching, by speeding up the retarded ones. The nature of this mechanism is under consideration.

Psychological Laboratory,

University of Cambridge.

${ }^{1}$ Lillie, F. R., The Development of the Chick, revised by Hamilton, H. I. (New York, 1952).

${ }^{2}$ McNally, E. H., and Byerly, T. C., Poult. Sci., 15, 280 (1936). s Witherby, H. F., Jourdain, F. C. R., Ticehurst, N. F., and Tucker, B. W.,
The Handbook of British Birds, 5 (London, 1949).

\section{Mammalian Intrafusal Muscle Fibres}

RECENT histological investigations of cat muscle spindles ${ }^{1-8}$ have established the presence of two types of muscle fibre, the large nuclear-bag fibres and the smaller and more numerous nuclear-chain fibres (Fig. $1 A$ ). Boyd ${ }^{3}$ maintains that each type of muscle fibre receives its own pattern of innervation, there being, in particular, a segregation in the size distribution of the fusimotor supply. However, earlier work by one of us ${ }^{4}$ described spindles in the quadriceps femoris of the rabbit which did not show this structural duality, since they were composed of nuclear-bag fibres only. We wished to ascertain the validity of this observation, and to determine the extent to which the muscle-fibre content of cat spindles represents the typical mammalian condition.
Cooper and Daniel ${ }^{5}$ found chain fibres to be the most numerous in the majority of human spindles sampled from neck and lumbrical muscles, but a few contained bag fibres only.

Nuclear-bag fibres are therefore a basic component of the mammalian spindle, whereas nuclear-chain fibres, though usually present in various proportions, may be lacking. A 'chain only' composition has been observed ${ }^{2}$ in part of a cat tandem spindle, but this condition is probably aberrant. Evidently most spindles in a particular mammal possess a similar type of fibre composition, though other types may occur. Thus the lagomorph spindle is typically 'bag only', but combinations with chain fibres also occur; human spindles may lack chain fibres, though typically they are present in excess.

In the cat spindle the secondary endings lie predominantly on the nuclear-chain fibres ${ }^{3}$; in the rabbit spindle they lie on the nuclear-bag fibres mainly in the myotube regions ${ }^{4}$ (hence the descriptive term 'myotube ending' suggested by Granit $\left.{ }^{6}\right)$. Both myotube and nuclear chain offer a similar substratum for the ending, and it is significant that the myotube regions in the rabbit are typically three to four times longer than those in the cat. The 'chain dominant' human spindle resembles the cat spindle in these respects ${ }^{5}$. As observed at or near the level of spindle entry, the motor innervation of the 'bag only' rabbit spindle is derived from both large and small fusimotor fibres (Barker ${ }^{4}$; Barker and Cope $^{7}$; Ip, unpublished observations) as in the cat ${ }^{3,7}$. Matthews ${ }^{8}$ has suggested that in the cat spindle these large and small motor fibres may represent functionally distinct types controlling the dynamic and static responses of the primary onding, respectively. The same correlation applied to the
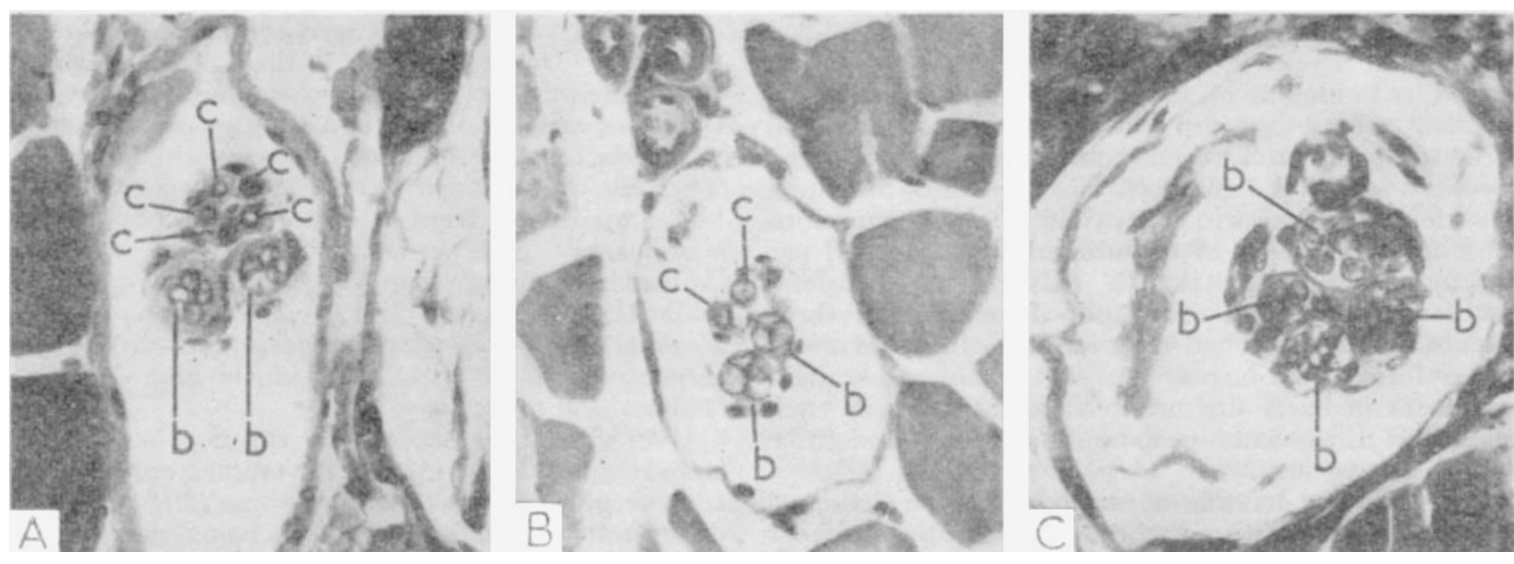

Fig. 1. Transverse sections through the equatorial region of spindles from cat soleus ( $A$ ), rat rectus femoris ( $B$ ), and rabbit vastus intermedius $(C)$ muscles. Nuclear-chain muscle fibres $(c)$ outnumber nuclear-bag muscle fibres $(b)$ in the cat $(2$ bag: 5 chain flbres); are present in equal proportion in the rat ( $2 \mathrm{bag}: 2$ chain fbres); and are absent in the rabbit ( 4 bag fibres only). (10 $\mu$ paraffin sections stained

Fourteen spindles from rabbit hind-limb muscles were traced from end to end in serial transverse section, 3 from vastus intermedius, 3 from tenuissimus, and 8 from soleus. All spindles possessed nuclear-bag fibres only, the most frequent number being 4 (Fig. $1 C$ ). This was also the case in 3 spindles from the vastus intermedius of a hare, and in 3 out of 6 spindles from a rabbit fore-limb muscle (extensor digitorum communis). The other spindles in this sample, however, possessed 3 bag fibres accompanied by 1 or 2 chain fibres.

The typical fibre content of the rat spindle proved to be 2 bag and 2 chain fibres (Fig. $1 B$ ); 8 spindles from rectus femoris and 6 from soleus had this composition In a further 3 spindles from soleus the proportion of bag to chain fibres was $2: 1,3: 1$, and $2: 3$. Samples of 3 spindles taken from a thigh flexor muscle of a hedgehog, a tree shrew, and an armadillo had bag-to-chain fibre ratios of $2: 2,2: 2$, and $2: 4$ or 5 , respectively. typical rabbit spindle would necessitate postulating a mechanism whereby this control could be achieved through the contraction of bag fibres only.

This work was supported in part by research grant NB-04149-01 from the National Institute of Neurological Diseases and Blindness, U.S. Public Health Service.

D. BARKER J. P. HUNT

Department of Zoology,

University of Durham.

${ }^{1}$ Boyd, I. A., J. Physiol., 153, $23 P$ (1960).

${ }^{2}$ Barker, D., and Gidumal, J. I., J. Physiol., 157, 513 (1961).

${ }^{3}$ Boyd, I. A., Phil. Trans. Roy. Soc., B, 245, 81 (1962).

4 Barker, D., Quart. J. Micro. Sci., 89, 143 (1948).

${ }^{6}$ Cooper, S., and Daniel, P. M., Brain, 86, 563 (1963).

6 Granit, R., Receptors and Sensory Perception (Yale University Press, 1955). Barker, D., and Cope, M., in Symp. Muscle Receptors, 263 (Hong Kong Univ. Press, 1962).

8 Matthews, P. B. C., Quart. J. Exp. Physiol., 47, 324 (1962). 